\title{
Occurrence and Significance of Secondary Iron-rich Products in Landfilled MSWI Bottom Ash
}

\author{
Saffarzadeh $\mathbf{A}^{1^{*}}$ and Takayuki Shimaoka ${ }^{1}$ \\ ${ }^{1}$ Department of Urban \& Environmental Engineering, Kyushu University, Fukuoka, 819-0395, Japan
}

*Corresponding author: Saffarzadeh A, Associate Prof. (Ph.D, D.Eng) Department of Urban \& Environmental Engineering, Kyushu University, Fukuoka, 819-0395, Japan, Tel: +81 (92) 802-3431; E-mail: amir@doc.kyushu-u.ac.jp

Received date: April 15, 2014; Accepted date: July 7, 2014; Published date: July 14, 2014

Copyright: ( 2014 Saffarzadeh A, et al. This is an open-access article distributed under the terms of the Creative Commons Attribution License, which permits unrestricted use, distribution, and reproduction in any medium, provided the original author and source are credited.

\begin{abstract}
Incineration is one of the most effective techniques for the treatment of both municipal and hazardous wastes. Via this technique, the majority of toxic substances are expected to be stabilized in the durable matrix of the end-ofprocess bottom ash products. These products consist of a variety of glassy/crystalline components including primary Fe-rich phases that may undergo alterations when exposed to natural environment. In the present research, the impact of natural weathering on the behavior of primary Fe-rich phases, their alteration, and the formation of the relevant secondary products in the weathered bottom ash samples of a (mono) landfill site was systematically investigated. Samples of various ages (1-20 yrs) were collected from four locations of the landfill in 2009. Optical microscopy, SEM-EDX, XRD and XRF examinations were applied in order to document the footprints of weathering processes. Using these techniques, we understood that several secondary (newly-formed) products (amorphous or crystalline) have been developed, including goethite $(\alpha-\mathrm{FeOOH})$, lepidocrocite $(\gamma-\mathrm{FeOOH})$, hematite $\left(\mathrm{Fe}_{2} \mathrm{O}_{3}\right)$, magnetite $\left(\mathrm{Fe}_{3} \mathrm{O}_{4}\right)$, iron oxide $(\mathrm{FeO})$, and $\mathrm{Fe}$-rich $\mathrm{Ca}-\mathrm{Si}$ and $\mathrm{Ca}$-Al-Si gel phases. They occurred under variable environmental conditions as the weathering products of the primary iron-rich phases. The strong affinity of these secondary phases with heavy metals of environmental significance such as $\mathrm{Zn}, \mathrm{Cu}, \mathrm{Pb}$, and $\mathrm{Ni}$ was also identified. This suggests that the development of secondary Fe-rich products can partially contribute to the reduction of heavy metals release to the surrounding environments. However such phenomena may have inhibitory effect on the utilization of bottom ash as recycled aggregates.
\end{abstract}

Keywords: Environment; Heavy metals; Landfill; MSW incineration bottom ash; Natural Weathering; Secondary Fe-rich products

\section{Introduction}

Incineration technology has been adopted as an effective strategy for the treatment of municipal and hazardous wastes in many communities at different scales with highest share among the developed countries. This treatment technique results in the generation of various residues including bottom ash and fly ash as the major solid outputs totally ranging from $4-10 \%$ by volume and $15-20 \%$ by weight of the original quantity of waste [1]. They predominantly consist of glassy phase and significant concentration of hazardous components comparing with the source materials. Among MSW incineration products, bottom ash is the most significant by-product that accounts for 85 to $95 \%$ of all the residues produced in the course of combustion [2].

Municipal solid waste incineration (MSWI) bottom ash is considered as biologically and chemically reactive residues whose long-term behavior and evolution have been comprehensively studied by several workers over the past two decades [3-6]; therefore its efficient management always remains one of the most controversial environmental topics. Among different treatment techniques, natural ageing and weathering has been considered as one of the most costeffective methods of treatment for the chemical stabilization of MSWI bottom ash. Many researchers have been investigating the natural or accelerated aging of bottom ash, a process which could also be applied to fly ash disposal [7-10].
In the incineration bottom ash a variety of primary iron-rich phases are present that behave differently when influenced by natural weathering processes. These phases may originate from the waste stream (e.g. metal iron and Fe-rich minerals) or may be formed in the course of incineration (e.g. magnetite spinels and metal inclusions). In either case, such phases become unstable and convert to secondary (or tertiary) products when exposed to natural weathering. The ironrelated reactions and products may trigger problems by generating unnecessary heat, gases, and leachate or cause staining when bottom ash is used as cement aggregate or when placed in the landfill.

These phenomena initiate immediately upon bottom ash characterization and persist for unlimited duration. To ad-dress such problems, a thorough understanding from the properties of the primary and secondary Fe-rich phases in the ash products is a requirement. The main goal of the current research was to study both fresh and weathered bottom ash with emphasis on the characterization of secondary (neo-formed) Fe-rich products in the weathered samples of a MSWI (mono) landfill site in the north east of the US. The impact of natural weathering on the behavior of Fe-rich phases, their alteration, and the formation of the relevant secondary products was systematically investigated. In the meantime, the strong affinity of these secondary phases with heavy metals of environmental significance such as $\mathrm{Zn}, \mathrm{Cu}, \mathrm{Pb}$, and $\mathrm{Ni}$ was also identified. This paper presents one major task of a large multipurpose project by specifically focusing on the characterization of secondary Fe-rich species in the landfilled incineration ash residues. 


\section{Iron in the Incineration Residues- An Overview}

Iron is one of the big 8 elements in the Earth's crust, being the fourth most abundant element (after oxygen, silicon and aluminum) at about $5 \%$ by weight [11]. Thanks to the combination of low cost and high strength, iron is the most used of all the metals. Iron is a very good conductor of both heat and electricity. It is also strong, ductile and malleable. Therefore, it is extensively mined, used and recycled throughout the world across an infinite variety of domains, from home to industry.

Metal iron may originate from various sources including household and municipal waste, curbside trash, industrial solid waste, and iron production waste. As a result of extensive utilization of iron in daily life, it is expected that a considerable fraction of this element enters the waste course and eventually incinerators as non-separable end-of-life material. Non-metallic iron also exists in a variety of inorganic components such as fine glass, ceramic, stone and mineral particles inherited from the waste stream that partially supply iron to the incineration residues. Hence, it is considerably enriched in the MSWI bottom ash ranging from 5-15\% [2] that is comparable with its crustal abundance as mentioned earlier. Metal iron and iron-bearing components of the waste convert to primary phases during the incineration and quenching processes that can alter to the secondary Fe-hydrate products (chiefly amorphous) and finely crystalline Fe-rich phases as a result of ageing or natural weathering phenomena. Formation of the secondary phases may continue or be inhibited upon ash disposal or recycling.

\section{Materials and Methods}

A field survey was conducted in September 2009 in order to collect naturally weathered MSWI bottom ash of different ages from different depths of Franklin (mono) landfill site in the state of New Hampshire, United States. Sampling was conducted within three consecutive days by excavating the deposited ash at four distinct locations A (1 yr), B (10 yrs), C (13-14 yrs), and D (20 yrs) (Figure 1). At each location, samples were collected from six levels- at depths $0,0.5,1,2,3$, and $4 \mathrm{~m}$ for locations A, B, C and 0, 0.5, 1, 1.5, 2, and $3 \mathrm{~m}$ for location D; all hereinafter referred to as points. Therefore, totally 24 sets of samples were collected. Several parameters including temperature, Eh and $\mathrm{pH}$ were measured on site at each point. In order to identify the characteristics of the primary Fe- rich minerals, we collected fresh (intact) bottom ash from three incineration plants in the US and Japan as well.

The collected ash samples from all sources were mixed manually, dried at ambient temperature and made into respective sub-samples using coning and quartering technique [12]. Sub-samples were sieved using a $2 \mathrm{~mm}$ screen in the laboratory to separate out the coarser grain intact particles from the fine-grained fraction. Several intact bottom ash particles were carefully picked out of the two size fractions for standard petrographic polished thin section preparation.

The thin sections were finely polished by diamond paste of $1 \mu \mathrm{m}$ for both polarized light and electron microscopy. They were observed through different optical modes (plane polarized light-PPL, cross polarized light-XPL, and reflected light-RL). Scanning electron microscopy coupled with quantitative energy-dispersive X-ray microanalysis (SEM-EDX) was performed for detailed, high-resolution grain-specific mineralogical and chemical data of various samples. With the emerging high-performance software technologies SEMEDX has become a standard method for the characterization and semi-quantitative analysis in various disciplines including material, mineral, environmental and biological sciences [13-15].

Backscattered electron (BSE) and characteristic X-ray images were taken by a scanning electron microscope, and the qualitative and qu0061ntitative spot analyses of the samples were conducted under accelerating voltages of $15-25 \mathrm{kV}$, the working distance (WD) of 17 $\mathrm{mm}$, a beam current of 3 to $5 \mathrm{nA}$, and a probe size of 5 in a high vacuum atmosphere with spectral acquisition time of 100-300 $\mathrm{s}$ at desired magnifications.

Selected samples were pulverized for bulk analyses. Semiquantitative bulk chemical analyses of the powdered samples were completed by using a Rigaku RIX3100 X-Ray fluorescence spectrometer (XRF) [16]. Powder X-Ray diffraction (XRD) analysis was also practiced in a Rigaku Multiflex diffractometer using $\mathrm{CuKa}$ radiation at $30 \mathrm{kV}$ voltage and $40 \mathrm{~mA}$ current in order to identify the existing crystalline phases (both primary and secondary) [17].

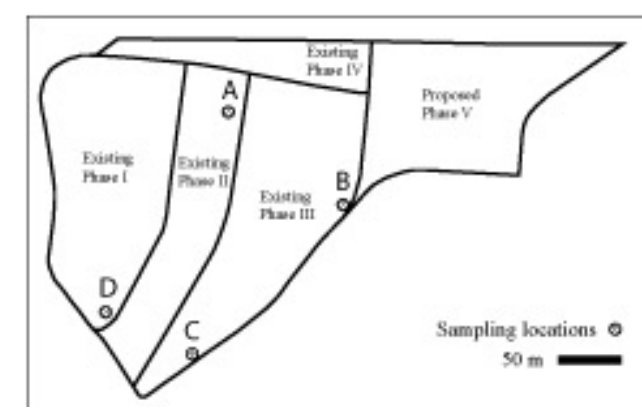

Figure 1: A schematic of the Franklin mono-landfill site representing the sampling locations (A, B, C and D).

\section{Results and Discussion}

\section{Primary iron-rich constituents of MSWI bottom ash}

MSWI bottom ash may contain a considerable amount of metalrich phases that are essentially made up of iron, aluminum and copper. These elements ( $\mathrm{Fe}$ and $\mathrm{Al}$ in particular) are concentrated in a variety of phases in the final ash products. Based on our microscopic and micro analytical experiments, it is possible to divide the metal-rich constituents of bottom ash into two groups: 1) metallic fragments (up to $3 \mathrm{vol} \%$ ) originated from the waste source, and 2) primary metal-rich minerals (up to $7 \mathrm{vol} \%$ ) that have been formed during the incineration process [18]. The first group is the remnant of larger metallic scraps typically with irregular shape ranging from several microns to a fraction of millimeter in size set in the bottom ash particle. Although they are essentially made up of $\mathrm{Fe}, \mathrm{Al}$ and $\mathrm{Cu}$ alloys, they may enclose minor amounts of other metals and non-metals $(\mathrm{Pb}, \mathrm{Sb}, \mathrm{Ni}, \mathrm{Si}, \mathrm{S}, \mathrm{P}$ etc). Such waste-derived metals assume to have been partially melted and contributed to the formation of the glassy matrix and primary metal-rich phase (second group) of the ash particles.

The members of the second group can be subdivided into metallic minerals (particularly magnetite spinels) and metal-rich inclusions. The magnetite spinel family is the most abundant primary iron oxide minerals within the incineration melt glass products. They present well-developed crystalline habits as well as irregular dendritic shape that are indicative of melt super-cooling and rapid quenching (Figure 
2a). These minerals have been shaped up as tightly-packed clusters of euhedral to subhedral microcrystals in the silicate glass matrix of the ash. The metal-rich inclusions as the other member of the second group are commonly found as discrete phases that are indicative of complete immiscibility with their host silicate glass (Figure 2b).
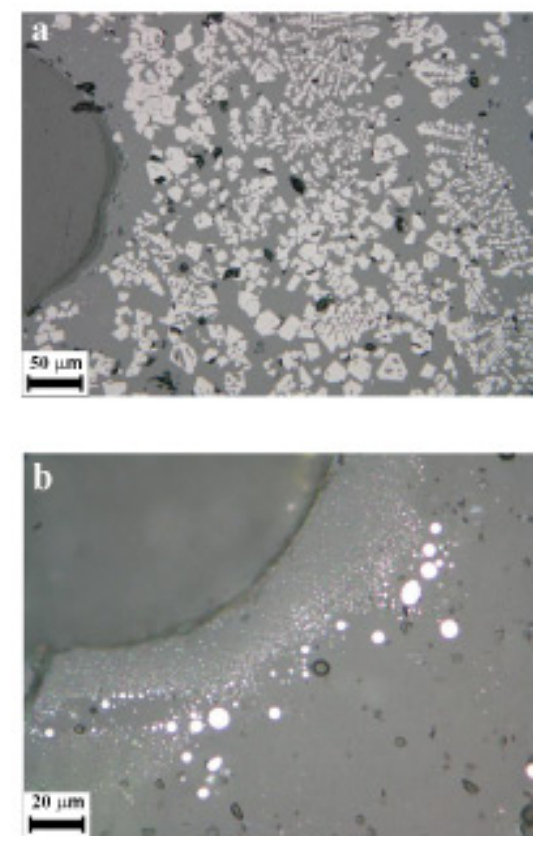

Figure 2: a) Microcrystals of magnetite spinel as a primary iron-rich phase (light gray) set within the glassy matrix (dark gray) of the incineration ash- RL; b) The spherical metal-rich inclusions (bright) as a primary iron-rich phase embedded in the glassy matrix (dark gray) of the incineration ash- RL.

Their sizes vary from submicron to several microns and are sphereshaped. Metallic iron (up to 90\%) and copper (up to 10\%) are the major components of the metal-rich inclusions; however some other elements such as $\mathrm{P}, \mathrm{Si}, \mathrm{Pb}, \mathrm{Zn}, \mathrm{Sb}, \mathrm{Sn}, \mathrm{Ni}$, and $\mathrm{S}$ might also be present at variable but lower concentrations.

Alteration of iron particles and interconversion of iron-rich phases are the most dominant weathering phenomena particularly in the older ash deposits of the landfill leading to the formation of secondary oxide and hydroxide iron species. Metallic minerals (spinels) and metal-rich inclusions display somewhat identical behavior as documented through the present study.

\section{Occurrence of Secondary Iron-rich Products}

Oxidation of metallic iron and iron-rich minerals at the presence of water and dissolved oxygen extensively occurs in nature or through industrial activities at broad Eh-pH ranges. The weathering processes convert the primary iron-rich phase to hydrate/oxide products through hydration/oxidation at different rates. As mentioned earlier, a variety of primary iron-bearing substances are present in the incineration bottom ash that may behave differently under the prevailing ash alkaline environment. Following our comprehensive examinations, the primary iron phases have been altered to a combination of secondary products including goethite partly with lepidocrocite (as hydrate phases), magnetite and hematite (as oxide phases), and several intermediate phases mixed with silicate and carbonate species.

Phases such as goethite and lepidocrocite are normally formed under oxidizing conditions as weathering products of iron-bearing minerals such as siderite, magnetite, pyrite, etc [19] through inorganic-chemical or organic precipitation from various kinds of $\mathrm{Fe}$ bearing solutions. The Fe-hydrates are the most dominant phases present in various zones of the landfill. Figure 3 shows the bulk iron concentration in the sampling locations (A through D); each column corresponds to the average iron concentration of all six sampling points in each location. Figure 4 presents the stability fields of several Fe-rich compounds as a function of redox potential (Eh) against $\mathrm{pH}$. The Eh and $\mathrm{pH}$ data obtained from every sampling point in the field was plotted in the diagram. The entire population is distributed in a linear arrangement and presents a broad range of $\mathrm{pH}$ from weakly to strongly alkaline and a narrow range of positive redox potential (oxic). Such environment theoretically favors the stability of hydrate iron compounds.

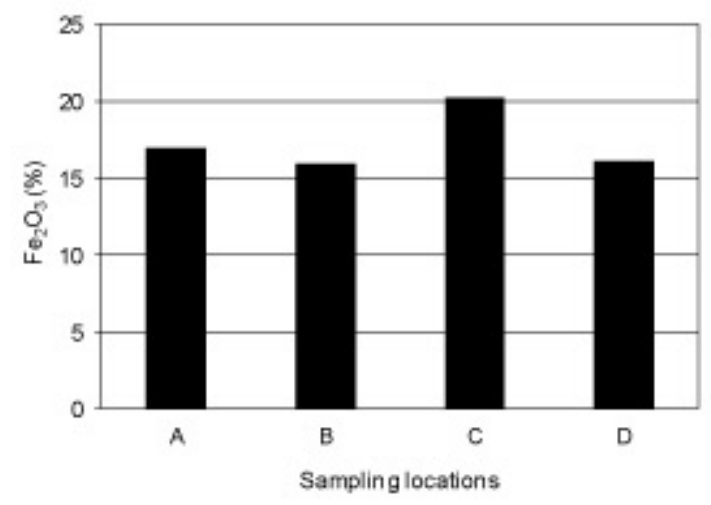

Figure 3: Average bulk iron concentration in the sampling locations (A to D).

An obvious trend in the transformation of primary Fe-bearing substances into secondary hydrate products and their distribution could not be delineated in the landfill, though evidences are indicative of higher concentrations of newly-formed Fe-rich species in the older ash deposits. Extensive formation of hydrate Fe-rich minerals, particularly goethite, can be corresponded to the weak to strong alkaline conditions (7.5- 11.5) and relatively oxidizing environment (average Eh of $0.3 \mathrm{~V}$ in locations A-C) (Figure 4). Under such conditions, most metallic iron and Fe-rich minerals are expected to become destabilized leading to the incipient formation of thermodynamically more stable hydrate Fe-rich species (mostly amorphous).

The oldest ash deposits (location D) is the richest zone with respect to the accumulation of Fe-rich hydrate phases. Although the average Eh in this location $(\sim 0.2 \mathrm{~V})$ is slightly below the other locations, the higher average $\mathrm{pH}(\sim 11)$ at all sampling depths of location D might have accelerated the transformation reactions. Schwertmann and Murad [20] suggest that the formation of goethite is strongly $\mathrm{pH}$ dependant and goethite is the only phase to form at $\mathrm{pH} 12$. Highly alkaline environment (and oxic condition) also favors the conversion of primary magnetite $(\mathrm{Fe} 3 \mathrm{O} 4)$ to goethite phase as confirmed by $\mathrm{He}$ 
Page 4 of 6

and Traina [21]. In addition, the role of burial time as another important factor should not be overlooked in the completion of such processes in location $\mathrm{D}$. The iron hydroxide precipitates present a broad variety of morphologies such as massive, crusty, fibrous, fanshaped (Fig. 5a), twisted (Fig. 5b) and convoluted habits. Such associations are usually amorphous or poorly crystalline. In some cases, the present crystals are aligned as parallel filaments or crisscrossed lamellar intergrowths.

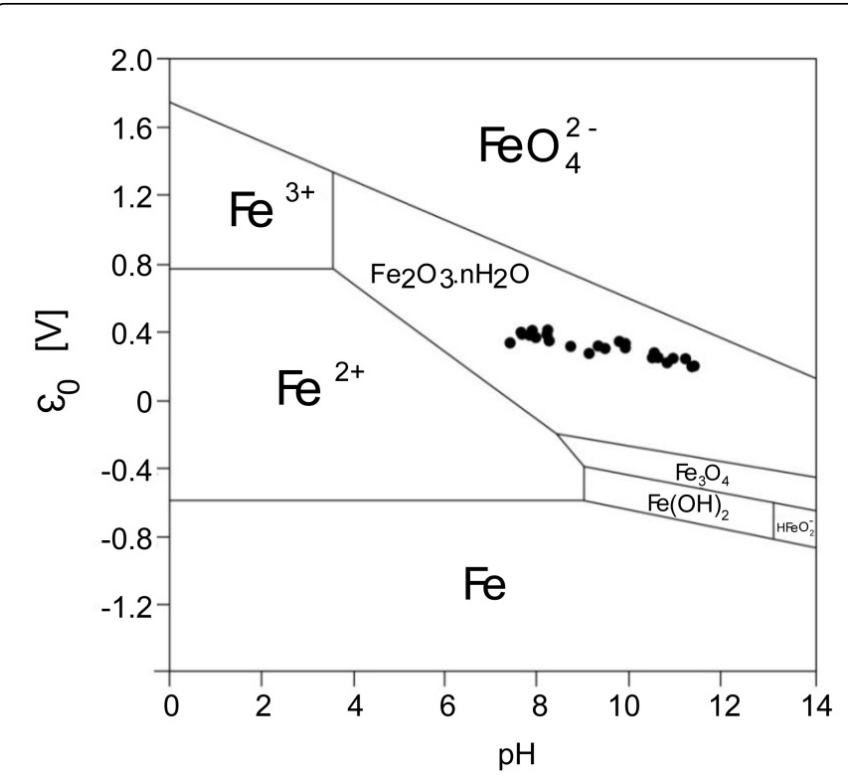

Figure 4: Eh-pH diagram of Fe-rich components at $25^{\circ} \mathrm{C}$ and 1 bar. Plots of the field-collected data display a linear arrangement in the diagram.

Although the Fe-hydrates were the most dominant phases in our landfill system, secondary magnetite (and partially hematite) are also present but at lesser quantities in several samples particularly from older locations C and D. Magnetite is a common mineral formed at elevated temperatures and pressures in igneous and metamorphic rocks; almost no magnetite is known to be formed inorganically in the biosphere [22]. It is therefore assumed that they have been formed in the landfill through the (biologicallycontrolled) dehydration/reduction of the secondary Fe-hydrate products. They have grown as individual euhedral to subhedral microcrystals (box-shaped or polygonal face) or aggregates of numerous crystals presenting linear or spherical orientations (Fig. 5c). Such morphologies display similarities with biologically synthesized magnetite from other works [23-24].

There were also evidences from the conversion of massive goethite to euhedral microcrystalline magnetite in a number of samples (Fig. $5 \mathrm{~d})$. This may indicate a local shift to more reducing condition by the solutions that locally transport ferrous iron in the landfill system at the scale of microenvironment that can be interpreted by the reaction no. 1. However there might be other alternatives for the production of Ferich species such as goethite, lepidocrocite, ferrihydrite, hematite and even magnetite. These species can all be produced from ferrous iron solutions by the oxidation of iron followed by hydrolysis via the basic reaction no.2 [25]. This reaction can be tuned in a manner to be consistent with the formation of various iron species.

$$
2 \mathrm{FeOOH}+\mathrm{Fe}^{2+} \rightarrow \mathrm{Fe}_{3} \mathrm{O}_{4}+2 \mathrm{H}^{+}(1)
$$

$2 \mathrm{Fe}^{2+}+2 \mathrm{H}_{2} \mathrm{O} \rightarrow 2 \mathrm{Fe}_{3}++\mathrm{H}_{2}+2 \mathrm{OH}^{-}(2)$

It should be noticed, however, that not all the primary Fe-rich phases have been affected by the dominating environmental condition in the ash deposits, since a significant amount of them have wholly or partly remained intact. This might have been resulted from variations in the chemistry of both host solid and percolating solutions at microscopic scale that has locally influenced the exchange reactions. The melt glass phase also protects a considerable amount of metal inclusions from weathering, although the end stage of the glass durability is not yet known. In addition, as observed in several occurrences, the newly-formed phases might have produced stable oxide-hydroxide films over the unstable phases as a barrier to the transport of reacting species. Cornell and Schwertmann [25] provide reasons for the decelerated corrosion rate of metallic iron based on recent opinion under similar condition. The extremely heterogeneous components of bottom ash particles and the irregular distribution of microfracturing networks are amongst other major reasons that can partly justify the disproportionate alteration of primary Fe-rich substances.

\section{Entrapment of Heavy Metals}

In order to evaluate the influence of the secondary Fe-rich phases on the entrapment (scavenging) of environmentally hazardous metals, over 35 points from those phases in the polished thin sections of various samples were analyzed by EDX of which 24 sets of data with higher accuracy were selected. The data are indicative of a wide range of compositional variations in the secondary Fe-rich species due to the presence of cations such as, $\mathrm{Si}, \mathrm{Ca}, \mathrm{Al}$ and other elements in the system; thereby a standard chemical formula cannot be reproduced for them. In most cases, however, based on oxygen concentration and the total amount of major cations $(\Sigma \mathrm{Fe}, \mathrm{Si}, \mathrm{Ca}, \mathrm{Al})$ - aided by microscopic observation and XRD results- it was possible to propose several nonstoichiometric compositions close to goethite (lepidocrocite), hematite, ferrous iron oxide, magnetite and inter-mediate versions for the existing species. Goethite is the best example of an isomorphously substituted iron oxide with maximum observed caption substitution [25].

From the current research, it was distinguished that the newlyformed Fe-rich phases play substantial role in the entrapment of most available heavy metals (in particular $\mathrm{Cu}, \mathrm{Ni}, \mathrm{Zn}$ and $\mathrm{Pb}$ ). This might have come into effect through a series of mechanisms including coprecipitation, complexation, adsorption and ion exchange with the solutions. $\mathrm{Cu}$ shows the highest affinity with the secondary Fe-rich phases- it was detected at almost $70 \%$ of the measurements (17 points) at moderately considerable quantities (0.31-5.14 wt \%). The amount of $\mathrm{Pb}$ enriched in the secondary Fe-rich phases is particularly high (0.82-9.91wt \%); although it was not frequently detected in such phases through our measurements. Correspondingly, the amount of $\mathrm{Ni}$ concentrated in these phases was about 0.13-0.9 wt\%, and that of $\mathrm{Zn}$ varied between $0.48-1.15 \mathrm{wt} \%$ at various analytical points.

Based on the microanalytical data, it is possible to suggest the adsorption selectivity of heavy metals in the following order: $\mathrm{Cu}>\mathrm{Ni}$ $>\mathrm{Zn}>\mathrm{Pb}$ onto the Fe-rich oxyhydroxides.

The problem, however, is that we do not know what portion of the total heavy metals inventory in the MSWI ash is bound to active sorption sites in equilibrium with the landfill leachate. 

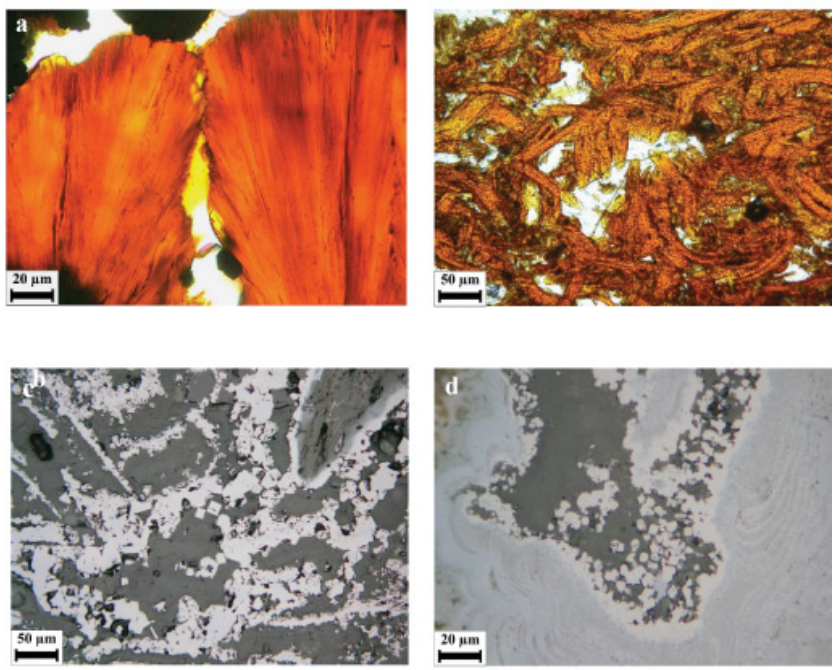

Figure 5: Photomicrographs of secondary Fe-rich products in the landfilled MSWI bottom ash formed during the weathering processes; semitranslucent orange-reddish fan-shaped (a) and fibrous (b) goethite from location $\mathrm{D}$ and $\mathrm{C}$ of the landfill, respectively- transmitted light (PPL), euhedral to subhedral microcrystals of magnetite- RL (c), and conversion of goethite to euhedral magnetite crystals (center) -RL (d). Both images " $c$ " and "d" are from the location $\mathrm{C}$ of the landfill

The SEM-EDX imagery technique was very useful for identifying the distribution pattern and elemental mapping of heavy metals in the secondary phases. Fig. 6a displays the backscattered electron (BSE) image of a secondary Fe-hydrate product (goethite) from the location $\mathrm{B}$ of the landfill. Figures $6 \mathrm{~b}$ and $6 \mathrm{c}$ are the characteristic X-ray images of the zones that are rich in $\mathrm{Fe}$ (densely concentrated) and $\mathrm{Pb}$, respectively. The heavy metals possess stronger effect in backscattering the electrons and therefore the dense population of brighter spots represents higher concentration of heavy metals particularly in the margins (Figure 6c).

\section{Conclusions}

We designed a systematic approach in order to evaluate the inorganic chemistry and mineralogical properties of MSWI bottom ash products when exposed to natural weathering in a full-scale MSWI mono (landfill) site. These products consist of a variety of glassy/ crystalline components including primary Fe-rich phases that may undergo alteration when exposed to natural environment. The current research focused on the importance and role of mineralogy as a practical tool in the identification of newly-formed (secondary) Ferich products upon landfilling.

Samples of various ages ( $0-20 \mathrm{yrs})$ were collected from four locations (A to D) of the landfill site. The novelty of the current research is that it could confirm the formation and transformation of secondary Fe-rich phases and their role in the entrapment of heavy metals using direct microscopic observation and micro beam measurements. In the meantime, bulk analytical techniques including $\mathrm{XRD}$ and XRF were employed as useful complementary methods.
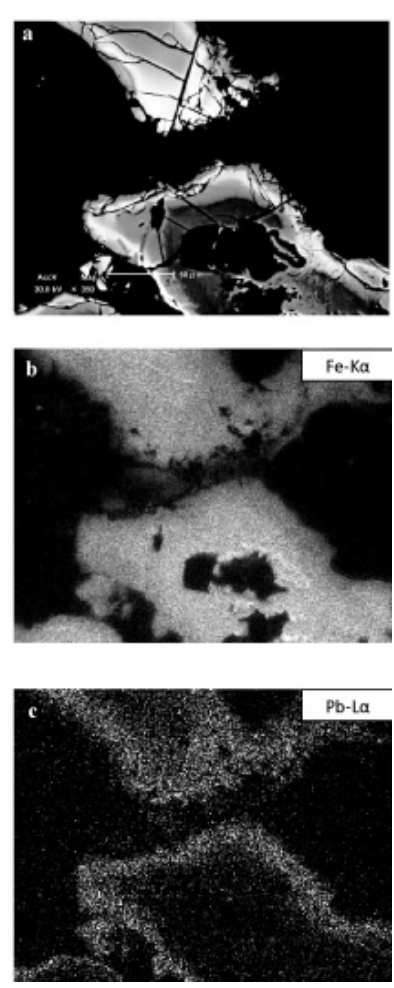

Figure 6: BSE image of a secondary iron hydrate aggregate (goethite) (a), and characteristic X-ray images of $\mathrm{Fe}$, and $\mathrm{Pb}$ (b and c) from location $\mathrm{B}$ of the landfill. The areas with higher heavy metal concentration appear brighter in the image " $c$ ".

The techniques presented here are directly applicable to a broad range of combustion residues from other sources. We summarize our achievements into the following categories:

- Depending on the prevailing physicochemical conditions in an incineration ash landfill, alteration reactions may initiate and persist for days or for years.

- The alkaline and oxic conditions in the landfill trigger the formation of various Fe-rich oxyhydroxides.

- Several secondary products (amorphous or crystalline) were identified, including goethite $(\alpha-\mathrm{FeOOH})$, lepidocrocite $(\gamma$ $\mathrm{FeOOH})$, hematite $\left(\mathrm{Fe}_{2} \mathrm{O}_{3}\right)$, magnetite $\left(\mathrm{Fe}_{3} \mathrm{O}_{4}\right)$, iron oxide $(\mathrm{FeO})$, and $\mathrm{Fe}$-bearing $\mathrm{Ca}-\mathrm{Si}$ and $\mathrm{Ca}-\mathrm{Al}-\mathrm{Si}$ gel phases that have been developed under variable environmental conditions as the weathering products of primary iron-rich phases.

- The formation rate of the secondary Fe-rich constituents is considerably time-dependent. They are more dominant in the older ash deposits particularly in the locations C and D of the landfill.

- Such altered phases present different stability fields and different behaviors with respect to heavy metal entrapment capacity.

- A strong correlation between the secondary Fe-rich products and heavy metals of environmental significance such as $\mathrm{Zn}, \mathrm{Cu}, \mathrm{Pb}$, and $\mathrm{Ni}$ was also identified. This suggests that the development of such products partially contribute to the reduction of heavy metals release to the landfill leachate. 
- Further investigation would be required to evaluate the formation condition and stability of secondary Fe-rich products, and their impacts on both the long-term stabilization of heavy metals and the utilization potential of bottom ash as recycled aggregates.

\section{Acknowledgement}

Financial support to this project was provided through a Grant-inAid for Japan-USA joint research project (approved by Gakushinkyo-2-9 on April 1. 2010) and Research Grant-in-Aid for Sustainable Society and Waste Management funded by the Ministry of Environment (K22078).

\section{References}

1. RenoSam, Rambøll (2006)The most efficient waste management system in Europe. Waste-to-energy in Denmark, Technical report.

2. Chandler AJ, Eighmy TT, Hartlén J, Hjelmar O et al. (1997) Municipal solid waste incinerator residues, Amsterdam: Elsevier Science B.V.

3. Belevi H, Stämpfli DM, Baccini P (1992)Chemical behavior of municipal solid waste incinerator bottom ash in monofills, Waste Manage.Res.10: 153-167.

4. Zevenbergen C, Reeuwijk LP, Bradley JP, Comans RNJ et al. (1998)Weathering of MSWI bottom ash with emphasis on the glassy constituents. J. Geochem. Explor 62: 293-298.

5. Chimenos JM, Fernández AI, Miralles L, Segarra M, Espiell F (2003) Short-term natural weathering of MSWI bottom ash as a function of particle size. Waste Manag 23: 887-895.

6. Piantone P, Bodénan F, Chatelet-Snidaro L (2004) Mineralogical study of secondary mineral phases from weathered MSWI bottom ash: implications for the modeling and trapping of heavy metals. Appl. Geochem 19:1891-1904.

7. Meima JA, Comans RNJ, (1997) Geochemical modeling of weathering reactions in municipal solid waste incinerator bottom ash. Environ. Sci. Technol 31:1269-1276.

8. Meima JA, Comans RNJ (1999) The leaching of trace elements from municipal solid waste incinerator bottom ash at different stages of weathering. Appl. Geochem 14: 159-171.

9. Marchese F, Genon G (2009) Full scale tests of short-term municipal solid waste incineration bottom ash weathering before landfill disposal. Am. J. Environ. Sci 5: 569-576.
10. Polettini A, Pomi R (2004) The leaching behavior of incinerator bottom ash as affected by accelerated ageing. J Hazard Mater 113: 209-215.

11. Abundance of Elements in Earth's Crust, HyperPhysics (2012) Georgia State University.

12. IUPAC (1990) Analytical Chemistry Division, Commission on Analytical Nomenclature. "Nomenclature for sampling in analytical chemistry. Pure Appl. Chem. 62: 193-1208.

13. Kang E, Park I, Lee YJ, Lee M (2012) Characterization of atmospheric particles in Seoul, Korea using SEM-EDX. J Nanosci Nanotechnol 12: 6016-6021.

14. Reed SJB (2005) Electron Microprobe Analysis and Scanning Electron Microscopy in Geology, second ed., Cambridge University Press, Cambridge, UK.

15. Schatten H (2013) Scanning Electron Microscopy for the Life Sciences, first ed., Cambridge University Press, Cambridge, UK.

16. Beckhoff B, Kanngießer B, Langhoff N, Wedell R, Wolff H (2006) Handbook of Practical X-Ray Fluorescence Analysis, Springer.

17. Suryanarayana C, Norton MG (1998) X-ray Diffraction: A Practical Approach. Microsc Microanal 4: 513-515.

18. Saffarzadeh A, Shimaoka T, Wei Y, Gardner KH, Musselman CN (2011) Impacts of natural weathering on the transformation/neoformation processes in landfilled MSWI bottom ash: a geoenvironmental perspective. Waste Manag 31: 2440-2454.

19. Deer WA, Howie RA, Zussman J (1980) An Introduction to the Rock Forming Minerals, London, UK: Longman Group Limited.

20. Schwertmann U, Murad E (1983) Effect of $\mathrm{pH}$ on the formation of goethite and hematite from ferrihydrite. Clay Clay Miner 31: 277-284.

21. He TY, Traina SJ (2004) Transformation of magnetite to goethite during $\mathrm{Cr}(\mathrm{VI})$ reduction under alkaline $\mathrm{pH}$ conditions., 227th American Chemical Society Meeting. Anaheim, CA, 446-449.

22. Lowenstam HA (1981) Minerals formed by organisms. Science 211: 1126-1131.

23. Amemiya Y, Arakaki A, Staniland SS, Tanaka T, Matsunaga T (2007) Controlled formation of magnetite crystal by partial oxidation of ferrous hydroxide in the presence of re-combinant magnetotactic bacterial protein Mms6. Biomaterials 28: 5381-5389.

24. Arakaki A, Nakazawa H, Nemoto M, Mori T, Matsunaga T (2008) Formation of magnetite by bacteria and its application. J R Soc Interface 5: 977-999.

25. Cornell RM, Schwertmann U (2003) The Iron Oxides: Structure, Properties, Reactions, Occurrences and Uses, Wiley-VCH. 